\title{
Person-Centered Maternity Care During Childbirth and Associated Factors at Selected Public Hospitals in Addis Ababa, Ethiopia, 2021: A Cross- Sectional Study
}

\author{
Azezew Ambachew Tarekegne \\ St Paul's Hospital Millennium Medical College \\ Berhanu Wordofa Giru ( $\nabla$ w.berhanu@yahoo.com ) \\ Addis Ababa University, College of Health Sciences,School of Nursing and Midwifery \\ https://orcid.org/0000-0003-2620-8785 \\ Bazie Mekonnen \\ Addis Ababa University College of Health Sciences
}

\section{Research Article}

Keywords: Person-centered maternity care, childbirth, Addis Ababa, Ethiopia

Posted Date: September 27th, 2021

DOl: https://doi.org/10.21203/rs.3.rs-915705/v1

License: (c) (1) This work is licensed under a Creative Commons Attribution 4.0 International License.

Read Full License 


\section{Abstract}

Background: Person-centered maternity care is respectful and responsive care to individual women's preferences, needs, and values and ensuring that their values guide all clinical decisions during childbirth. It is recognized as a key dimension of the quality of maternity care that increases client satisfaction and institutional delivery. However, little research has been conducted about person-centered maternity care in Ethiopia.

Objective: The aim of this study was to assess the status of person-centered maternity care and associated factors among mothers who gave birth at selected public hospitals in Addis Ababa city, Addis Ababa, Ethiopia, 2021.

Method: A facility-based cross-sectional study was conducted at selected public hospitals in Addis Ababa city. A semi-structured questionnaire was used to collect data from post-natal mothers selected by systematic random sampling. The data was coded and entered using Epi-data version 4.6 and analyzed using SPSS version 25. Bivariate and multivariable linear regression analysis was used to identify factors associated with person-centered maternity care. The strength of association between independent and dependent variables was reported by using unstandardized $\beta$ at $95 \% \mathrm{Cl}$ and $p$-value $<0.05$ were considered statistically significant.

Results: In this study 384 mothers were participated with a response rate of $99.2 \%$. The overall prevalence of person-centered maternity care was $65.8 \%$. Respondents who had no ANC follow-up ( $\beta=-5.39,95 \% \mathrm{Cl}$ : $-10.52,-0.26)$, <4 ANC follow up ( $\beta=-3.99,95 \% \mathrm{Cl}:-6.63,-1.36)$, night time delivery $(\beta=-3.95,95 \% \mathrm{Cl}:-5.91$, $-1.98)$ and complications during delivery $(\beta=-3.18,95 \% \mathrm{Cl}:-6.01,-0.35)$ were factors significantly associated with person-centered maternity care.

Conclusion and Recommendations: The finding of this study showed that the proportion of personcentered maternity care among mothers who gave birth in public hospitals of Addis Ababa was high as compared to previous studies. The factors affecting person-centered maternity care are manageable to interventions. Therefore, Health care providers need to provide person-centered maternity care for all mothers.

\section{Plain Of English Summary}

$>$

Person-centered maternity care is a key dimension of the quality of maternity care that recognizes user experience and affects health-seeking behavior leading to decreased maternal and neonatal complications, postpartum depression, and maternal dissatisfaction. Client exit interview of 384 mothers were enrolled from those mothers who gave birth in selected public health hospital with an overall prevalence of $65.8 \%$. Respondents who had no ANC follow-up, $<4$ ANC follow up, night time delivery, and complications during delivery were factors that were found to be associated with person-centered maternity care. 
Health care providers, Health institutions, Policy makers and Health sector officials should design and implement strategies to provide highlighted dignity and respect, communication and autonomy, and supportive care for all mothers during labor and delivery.

\section{Introduction}

\subsection{Background}

Person-centered maternity care (PCMC) is defined as providing maternity care that's responsive and respectful to individual women's preferences, values, and needs; ensuring that women's values guide all clinical decisions during labor and childbirth ${ }^{[1,2]}$. The world health organization (WHO) recommendations highlighted dignity and respect, communication and autonomy, and supportive care during childbirth as key components of PCMC that should be provided for all mothers during labor and delivery. It aims to improve communication between health care providers and women to promote the utilization of care ${ }^{[3,4]}$.

Person-centered care during childbirth is identified as a key dimension of the quality of maternity care. It recognizes user experience and affects health-seeking behavior ${ }^{[3]}$. Studies showed that the PCMC approach can lead to decreased maternal and neonatal complications, postpartum depression, and improved patient satisfaction. Moreover, when women feel respected and experience compassion from care providers during labor and delivery they are more likely to return for postpartum maternal health services ${ }^{[5-7]}$.

Poor quality of care contributes to high maternal mortality in developing countries, especially in SubSaharan. About three-quarters of maternal deaths are due to complications of labor, childbirth, and the first 24 hours postpartum after delivery ${ }^{[8,9]}$.Evidence showed that person-centered maternity care plays an important role in the identification of complications during facility-based childbirth thus reducing maternal mortality and morbidity significantly. Moreover, PCMC emphasizes the quality of patient experience by helping the women to feel safe and at ease to communicate how she feels and what she needs to the health care provider ${ }^{[5,10]}$.

Poor person-centered maternity care which is characterized by disrespectful and abusive treatment of women during facility-based childbirth can deter women from giving birth in health facilities and lead to poor maternal and neonatal outcomes ${ }^{[11-14]}$. It has psychological effects for mothers, a higher risk of dissolution and risk for families, and the potential poverty of thousands due to high costs of care ${ }^{[15,16]}$.

Advancing PCMC approaches in maternal health services is essential to improve client satisfaction, increase facility-based deliveries and ensure effective implementation of women's rights ${ }^{[6,15]}$. Efforts to increase maternal utilization of health services in low and middle-income countries are not possible to achieve the desired goals without improving women's experience of care. Other studies showed that women intent to give birth in an environment where they feel safe, valued, and respected ${ }^{[4,12,17]}$. 
A study in low and middle-income countries revealed that mothers were not experiencing person-centered maternity care. This study reported that women were receiving the highest mean PCMC score $(66.9 \%)$ in urban Kenya and the lowest PCMC score (51.6\%) in rural Ghana. The study reported that health care providers never introduced themselves for $90 \%$ of mothers, $53 \%$ of women in Kenya, and $73 \%$ of women in India were not asked permission from health care providers before doing procedures ${ }^{[18]}$.

Evidences showed that person-centered maternity care was affected by the socioeconomic status of the women and by health facility level ${ }^{[10,18,19]}$. A study done in Kenya found that wealthier, employed, literate and married women experienced higher person-centered maternity care scores as compared to poorer, unemployed, illiterate, and unmarried women respectively ${ }^{[8]}$.

A study done in Ethiopia reported that $64.5 \%$ of women experienced person-centered maternity care. This study also showed that person-centered maternity care increases client satisfaction and influence healthseeking behavior of the women ${ }^{[2]}$. On the other hand, poor person-centered maternity care results in decreased institutional delivery ${ }^{[20,21]}$. Residence, average monthly income, having ANC follow-up, time of delivery, mode of delivery, complication during childbirth, and length of stay in the health facility were factors affecting person-centered maternity care ${ }^{[2,22-25]}$.

Several studies have been conducted to identify determinant factors of person-centered maternity care in different countries. However, little research has been conducted in Ethiopia about person-centered maternity care during facility-based childbirth. Therefore this study aimed to assess the status of personcentered maternity care during childbirth and associated factors at public hospitals in Addis Ababa, Ethiopia.

\section{Methods}

\section{Study Area, Period and Design}

A facility-based cross-sectional study was conducted in public hospitals of Addis Ababa city from February 15 to March 14/2021. Addis Ababa is the capital city of Ethiopia and covers an area of 527 kilometers. According to the 2007 census the city has a total population of $3,384,569^{[26]}$. There are 13 governmental hospitals in the city. From these five hospitals are administered under the Federal Ministry of Health, six managed by Addis Ababa health bureau, one under the police force, and one governed by the armed force. However, twelve hospitals out of thirteen provide labor and delivery services. The study was conducted in Tikur Anbessa Specialized Hospital, St. Paul's Hospital Millennium Medical College, Gandhi Memorial Hospital, and Yekatit 12 Hospital.

Tikur Anbessa Specialized Hospital is a referral and teaching hospital under the Ministry of Education of Ethiopia. St. Paul's Hospital Millennium Medical College is a specialized and teaching hospital managed under the Federal Ministry of Health. Gandhi Memorial Hospital and Yekatit 12 Hospital are governmental hospitals administered under the Addis Ababa health bureau. 


\section{Population, sample size determination and sampling technique}

The source population was all women who gave birth at selected public hospitals in Addis Ababa and the study population were randomly selected women (aged above 18years) who gave birth in selected hospitals of Addis Ababa during the data collection period.

The sample size was determined by using a single population proportion formula. A previous study conducted to assess the determinants of person-centered maternity care in Dessie town, Ethiopia reported the prevalence of person-centered maternity care was $64.5 \%{ }^{[2]}$. This study used the assumption of standard normal distribution at a $95 \%$ confidence level and a margin of error assumed to be $5 \%$.Considering a non-response rate of $10 \%$, the final sample size was 387 .

Four hospitals were selected out of thirteen governmental hospitals in Addis Ababa by simple random sampling. Therefore, Tikur Anbessa Specialized Hospital, Gandhi Memorial Hospital, St. Paul's Hospital Millennium Medical College, and Yekatit 12 Hospital were the required hospitals for this study. The total sample size (387) was allocated proportionally to each of the selected hospitals by reviewing the number of deliveries attended in each hospital. A systematic random sampling technique was used to collect data using the women's delivery registration logbook during the study period in each hospital. $K=N / n=$ $2050 / 387=5$. So every fifth mother was interviewed.

\section{Study Variables}

The dependent variable was person-centered maternity care and the independent variables included socio-demographic characteristics (age, marital status, residence, level of education, employment status, and monthly income), obstetrics related factors (parity, ANC, mode of delivery, time of delivery, previous delivery experience, complication during delivery, newborn outcome, sex of delivery attendant, and profession of delivery provider) and facility characteristics such as availability of infrastructure and length of stay at a health facility.

\section{Operational Definitions}

\section{Person-Centered Maternity Care}

Person-centered maternity care was measured by using the PCMC scale. The PCMC scale has three domains: dignity and respect, communication and autonomy, and supportive care and 30 items with each item having a four-point response scale, that is 0- 'no, never', 1- 'yes, a few times, 2- 'yes, most of the time' and $3-$ 'yes, all the time'. The negative items such as physical abuse, verbal abuse, auditory privacy, and crowdedness of the room questions were reversely coded so that the highest score represents good care. The total PCMC score is a summative score from the response to individual items which ranges from 0 to $90[2,10]$.

\section{Dignity and Respect}


Measured by using six items with each item having a four-point response scale, that is, 0- 'no, never', 1-'yes, a few times, 2- 'yes, most of the time' and 3- 'yes, all the time'.

\section{Communication and Autonomy}

Measured by using nine items with each item having a four-point response scale, that is, 0- 'no, never', 1'yes, a few times, 2- 'yes, most of the time' and 3- 'yes, all the time'.

\section{Supportive Care}

Measured by using fifteen items with each item having a four-point scale, that is, 0- 'no. never', 1- 'yes, a few times, 2- 'yes, most of the time' and 3- 'yes, all the time'.

\section{Data Collection Tool and Procedures}

Semi-structured questionnaires which have socio-demographic characteristics of the mother, obstetrics history, and person-centered maternity care scale were used to collect the data from study participants. The tool was validated in different low and middle-income countries including Ethiopia to assess personcentered care for developing settings. The scale has good internal reliability with Cronbach's alpha above $0.8^{[2,8,27]}$.

The data was collected from mothers who gave birth in selected public health hospitals using a standardized, pretested, and structured Amharic version questionnaire. Four Diploma Midwives were recruited for data collection and two Bachelors of sciences Midwives were assigned for supervision.

\section{Data Quality Assurance}

The questionnaire for data collection was prepared first in English and translated into Amharic and backtranslated to English to keep the consistency of the data. One-day training was given to data collectors and supervisors by investigators. Additionally, a pre-test of the questionnaire was done on $5 \%$ of the sample size (20 women) who gave birth in Zewditu Memorial Hospital in Addis Ababa City. The data was checked daily for its completeness and consistency by the investigator and supervisors.

\section{Data Processing and Analysis}

The data were checked for completeness, cleaned manually, coded and entered into Epi-data version 4.6 software, and exported to SPSS version 25 for further analysis. Descriptive statistics were presented using tables and figures.

After creating dummy variables simple linear regression analysis was used primarily to check which variables had an association with dependent variable. The assumption of linearity was checked by plotting a P-P plot and normality was checked by using Q-Q plots and histogram. Multi co-linearity assumption was checked by Variance Inflation Factor (VIF) and there is no multi co-linearity. Variables having $p$-value $\leq 0.25$ in simple linear regression were entered into multiple linear regressions for 

were identified by using unstandardized $\beta, 95 \%$ confidence interval $(\mathrm{Cl})$, and $p$-value $\leq 0.05$.

\section{Results}

\section{Socio-demographic characteristics of the respondents}

In this study, 384 mothers were participated with a response rate of $99.2 \%$. Most of the study participants $328(85.4 \%)$ were from Addis Ababa. The mean age of the mothers was 26 (SD, \pm 3.87 ) years with a minimum and maximum age of 18 and 40 years respectively.

Almost all of the respondents 369 (96.1\%) were married. Out of the total respondents, 165 (43\%) had a primary level of education. Regarding occupation, 226 (58.8) were housewives. The mean monthly income of the respondents was 3384 birr (Table 1). 
Table 1

Socio demographic characteristics of the respondents at public hospitals of Addis Ababa, Ethiopia, $2021(n=384)$

\begin{tabular}{|c|c|c|}
\hline Variables & Frequency & Percentage (\%) \\
\hline \multicolumn{3}{|l|}{ Residence } \\
\hline Urban & 328 & 85.4 \\
\hline Rural & 56 & 14.6 \\
\hline \multicolumn{3}{|l|}{ Age of mothers } \\
\hline$\leq 24$ & 149 & 38.8 \\
\hline $25-29$ & 160 & 41.7 \\
\hline$\geq 30$ & 75 & 19.5 \\
\hline \multicolumn{3}{|l|}{ Marital status } \\
\hline Married & 369 & 96.1 \\
\hline Unmarried & 15 & 3.9 \\
\hline \multicolumn{3}{|l|}{ Level of education } \\
\hline Unable to read and write & 23 & 6 \\
\hline Primary school (grade 1-8) & 165 & 43 \\
\hline Secondary school (grade 9-12) & 118 & 30.7 \\
\hline Diploma and above & 78 & 20.3 \\
\hline Occupation & 226 & 58.8 \\
\hline Housewife & 34 & 8.9 \\
\hline Government employee & 124 & 32.3 \\
\hline \multicolumn{3}{|l|}{ Private employee } \\
\hline \multicolumn{3}{|l|}{ Income } \\
\hline $0-1650$ & 62 & 16.1 \\
\hline $1651-3200$ & 174 & 45.3 \\
\hline$>3200$ & 148 & 38.6 \\
\hline
\end{tabular}

\section{Obstetrics characteristics of the respondents}

From the total 384 study participants, almost all of 369 (96.1\%) had antenatal care (ANC) follow-up for current delivery. Besides, nearly a quarter of the respondents $274(74.3 \%)$ had received four and above ANC visits. 
About $231(60.2 \%)$ of the mothers were multiparous. Almost half of the mothers $188(49 \%)$ had delivered through spontaneous vaginal delivery and $261(68 \%)$ of deliveries were attended by Doctors. Over half of mothers 211 (54.9\%) had gave birth in the daytime. Most of the respondents 329 (85.7\%) had no complications during delivery. Among the total respondents, 148 (36.8\%) had more than two days of hospital stay (Table 2). 
Table 2

Obstetrics characteristics of the respondents at public hospitals of Addis Ababa, Ethiopia, $2021(\mathrm{n}=384)$

\begin{tabular}{|lll|}
\hline Variables & Frequency & Percentage (\%) \\
\hline ANC & & \\
Yes & 369 & 96.1 \\
No & 15 & 3.9 \\
\hline Number of ANC & & \\
$<4$ & 95 & 25.7 \\
$\geq 4$ & 274 & 74.3 \\
\hline Parity & & \\
Primiparous & 153 & 39.8 \\
Multiparous & 231 & 60.2 \\
\hline Number of facility based delivery & & \\
1 & 156 & 40.6 \\
$\geq 2$ & 228 & 59.4 \\
\hline Mode of delivery & & \\
Spontaneous vaginal delivery & 188 & 49 \\
Cesarean section & 176 & 45.8 \\
Instrumental & 20 & 5.2 \\
\hline Profession of delivery attendant & & \\
Doctor & 261 & 68.9 \\
Midwife & 123 & 32.1 \\
\hline Sex of provider conducting delivery & & \\
Male & 248 & \\
Female & 116 & \\
Both & 20.2 \\
\hline Time of delivery & & \\
Day & & \\
Night & & \\
\hline
\end{tabular}




\begin{tabular}{|c|c|c|}
\hline Variables & Frequency & Percentage (\%) \\
\hline \multicolumn{3}{|l|}{ Complication during delivery } \\
\hline Yes & 55 & 14.3 \\
\hline No & 329 & 85.7 \\
\hline \multicolumn{3}{|l|}{ Newborn outcome } \\
\hline Alive & 368 & 95.8 \\
\hline Died & 16 & 4.2 \\
\hline \multicolumn{3}{|l|}{ Length of stay in the hospital } \\
\hline One day & 186 & 48.4 \\
\hline Two days & 50 & 13 \\
\hline More than two days & 148 & 38.6 \\
\hline
\end{tabular}

Person-centered maternity care during childbirth was defined as a summative score from the response to each item which ranges from 0 to 90 . The mean person-centered maternity care score of the respondents was $59.2(S D= \pm 10.1)$ out of 90 with the minimum and maximum PCMC scores of 33 and 82 from 90 respectively. The percentage mean PCMC score of the respondents was $65.8 \%$.

\section{Dignity and Respect}

The mean dignity and respect score of the respondents was $15.7(\mathrm{SD}= \pm 2.15)$ out of 18.About 133 $(34.6 \%)$ of the study participants were treated with respect and $128(33.3 \%)$ of participants were treated in a friendly manner during their stay in the facility. Only $15(3.9 \%)$ and $4(1 \%)$ of mothers had experienced verbal or physical abuse at least on times in the facility respectively. In addition, $7(1.8 \%)$ had reported their auditory privacy was not kept and $9(2.3 \%)$ felt their health information was not kept confidential (Table 3). 
Table 3

Distribution of dignity and respect items in public hospitals of Addis Ababa, Ethiopia, 2021 $(n=384)$

\begin{tabular}{|lllll|}
\hline Items & $\begin{array}{l}\text { No, } \\
\text { never } \\
(\%)\end{array}$ & $\begin{array}{l}\text { Yes, a few } \\
\text { times (\%) }\end{array}$ & $\begin{array}{l}\text { Yes, most of } \\
\text { the time (\%) }\end{array}$ & $\begin{array}{c}\text { Yes, all the } \\
\text { time (\%) }\end{array}$ \\
\hline Providers treat me with respect & $5(1.3)$ & $41(10.7)$ & $205(53.4)$ & $133(34.6)$ \\
\hline Provider treat me in a friendly manner & $\begin{array}{l}12 \\
(3.1)\end{array}$ & $39(10.2)$ & $205(53.4)$ & $128(33.3)$ \\
\hline $\begin{array}{l}\text { Providers shouted, insulted, scolded, } \\
\text { threatened or talked me rudely (RC) }\end{array}$ & $\begin{array}{l}360 \\
(93.7)\end{array}$ & $15(3.9)$ & $8(2.1)$ & $1(0.3)$ \\
\hline $\begin{array}{l}\text { Providers pushed, slapped, beaten, pinched } \\
\text { or physically restrained (RC) }\end{array}$ & $\begin{array}{l}378 \\
(98.5)\end{array}$ & $4(1)$ & $2(0.5)$ & 0 \\
\hline $\begin{array}{l}\text { People not involved in the care hear } \\
\text { discussion with the provider (RC) }\end{array}$ & $\begin{array}{l}354 \\
(92.2)\end{array}$ & $7(1.8)$ & $19(5)$ & $4(1)$ \\
\hline $\begin{array}{l}\text { Feel health information was or will be kept } \\
\text { confidential }\end{array}$ & $\begin{array}{l}17 \\
(4.4)\end{array}$ & $9(2.3)$ & $91(23.7)$ & $267(69.6)$ \\
\hline RC = Reverse Coded & & & & \\
\hline
\end{tabular}

\section{Communication and Autonomy}

The mean communication and autonomy score of the respondents was $14.62(S D= \pm 4)$ from 27. Most of the respondents $316(82.3 \%)$ had reported providers never introduced themselves. From the total respondents, 124 (32.3\%) of mothers reported that providers never called by their name. Only 88 (22.9\%) of respondents had involved in decisions about their care during their stay in the facility. In addition 24 $(6.3 \%)$ of the respondents reported that providers never asked consent before doing examinations and procedures.

Among the study participants, $233(60.7 \%)$ of mothers were not allowed to be in a position of choice during delivery. Only 96 (25\%) of the respondents reported that the purpose of medicines they took was explained and $67(17.4 \%)$ of respondents reported that they could ask any questions they had to health care providers (Table 4). 
Table 4

Distribution of communication and autonomy items in public hospitals of Addis Ababa, Ethiopia, 2021(n $=384$ )

\begin{tabular}{|c|c|c|c|c|}
\hline Items & $\begin{array}{l}\text { No, } \\
\text { never } \\
(\%)\end{array}$ & $\begin{array}{l}\text { Yes, a few } \\
\text { times (\%) }\end{array}$ & $\begin{array}{l}\text { Yes, most of the } \\
\text { time (\%) }\end{array}$ & $\begin{array}{l}\text { Yes, all the } \\
\text { time (\%) }\end{array}$ \\
\hline Providers introduced themselves & $\begin{array}{l}316 \\
(82.3)\end{array}$ & $45(11.7)$ & $21(5.5)$ & $2(0.5)$ \\
\hline Providers call me by my name & $\begin{array}{l}124 \\
(32.3)\end{array}$ & $95(24.7)$ & $117(30.5)$ & $48(12.5)$ \\
\hline Involved in decisions & $20(5.2)$ & $55(14.3)$ & $221(57.6)$ & $88(22.9)$ \\
\hline $\begin{array}{l}\text { Consent before doing examinations } \\
\text { and procedures }\end{array}$ & $24(6.3)$ & $50(13)$ & $215(56)$ & $95(24.7)$ \\
\hline Allowed position of choice & $\begin{array}{l}233 \\
(60.7)\end{array}$ & $83(21.6)$ & $62(16.1)$ & $6(1.6)$ \\
\hline $\begin{array}{l}\text { Providers speak in a language that I } \\
\text { could understand }\end{array}$ & $5(1.3)$ & $12(3.1)$ & $104(27.1)$ & $263(68.5)$ \\
\hline $\begin{array}{l}\text { Purpose of examinations and } \\
\text { procedures were explained }\end{array}$ & $15(3.9)$ & $53(13.8)$ & $222(57.8)$ & $94(24.5)$ \\
\hline Purpose of medicines explained & $24(6.3)$ & $45(11.7)$ & $219(57)$ & $96(25)$ \\
\hline I could ask any questions I had & $10(2.6)$ & $77(20.1)$ & $230(59.9)$ & $67(17.4)$ \\
\hline
\end{tabular}

\section{Supportive Care}

The mean supportive care score of the respondents was $28.84(\mathrm{SD}= \pm 5.78)$ out of 45 . Most of the respondents $200(52.1 \%)$ and $329(85.7 \%)$ were not allowed to have companions during labor and delivery respectively. Out of the total respondents, $114(29.7 \%)$ of them had reported that there were enough health care providers to care for them. In addition, 17 (4.4\%) of mothers felt that the rooms were crowded during their stay in the facility.

Over half of the respondents, 203 (52.9\%) reported that there was water in the facility and most of participants 331 (86.2) reported the facility had electricity. Nearly half of the study participants 198 $(51.8 \%)$ reported that they felt safe during their stay in the facility. Only $49(12.8 \%)$ of mothers reported that they thought the general environment of the facility was very clean (Table 5). 
Table 5

Distribution of supportive care items in public hospitals of Addis Ababa, Ethiopia, 2021 $(n=384)$

\begin{tabular}{|lllll|}
\hline Items & $\begin{array}{l}\text { No, never } \\
(\%)\end{array}$ & $\begin{array}{l}\text { Yes, a few } \\
\text { times (\%) }\end{array}$ & $\begin{array}{l}\text { Yes, most of the } \\
\text { time (\%) }\end{array}$ & $\begin{array}{c}\text { Yes, all the } \\
\text { time (\%) }\end{array}$ \\
\hline Allowed a labor companion & $\begin{array}{l}200 \\
(52.1)\end{array}$ & $59(15.4)$ & $72(18.7)$ & $53(13.8)$ \\
\hline Allowed a delivery companion & $\begin{array}{l}329 \\
(85.7)\end{array}$ & $25(6.5)$ & $20(5.2)$ & $10(2.6)$ \\
\hline $\begin{array}{l}\text { Providers talk to me about my } \\
\text { feeling }\end{array}$ & $21(5.5)$ & $119(31)$ & $212(55.2)$ & $32(8.3)$ \\
\hline $\begin{array}{l}\text { Providers supported anxieties } \\
\text { and fears }\end{array}$ & $16(4.2)$ & $73(19)$ & $255(66.4)$ & $40(10.4)$ \\
\hline $\begin{array}{l}\text { Providers try to control when I } \\
\text { have a pain }\end{array}$ & $5(1.3)$ & $73(19)$ & $256(66.7)$ & $50(13)$ \\
\hline $\begin{array}{l}\text { Providers paid attention when I } \\
\text { need help }\end{array}$ & $6(1.5)$ & $59(15.4)$ & $248(64.6)$ & $71(18.5)$ \\
\hline Providers took best care for me & $8(2.1)$ & $42(10.9)$ & $214(55.7)$ & $120(31.3)$ \\
\hline I trust providers regards to care & $4(1)$ & $16(4.2)$ & $84(21.9)$ & $280(72.9)$ \\
\hline There was enough providers & $6(1.5)$ & $29(7.6)$ & $235(61.2)$ & $114(29.7)$ \\
\hline The rooms were crowded (RC) & $\begin{array}{l}103 \\
(26.8)\end{array}$ & $118(30.8)$ & $146(38)$ & $17(4.4)$ \\
\hline There was water in the facility & $38(9.9)$ & $68(17.7)$ & $75(19.5)$ & $203(52.9)$ \\
\hline There was electricity in facility & $2(0.5)$ & $2(0.5)$ & $49(12.8)$ & $331(86.2)$ \\
\hline Feel safe in the facility & $1(0.3)$ & $18(4.7)$ & $167(43.5)$ & $198(51.5)$ \\
\hline Waiting time & $\begin{array}{l}\text { Very } \\
\text { long }\end{array}$ & $\begin{array}{l}\text { Somewhat } \\
\text { long }\end{array}$ & Little long & Very short \\
\hline facility & $11(2.9)$ & $105(27.3)$ & $196(51)$ & $49(12.8)$ \\
\hline RC = Reverse Coded & $\begin{array}{l}\text { Very } \\
\text { dirty }\end{array}$ & $\begin{array}{l}\text { Dirty } \\
8(2.1)\end{array}$ & $327(85.1)$ & Clean \\
\hline
\end{tabular}

As shown in Fig. 1, the percentage mean person-centered maternity care score of the respondents was $65.8 \%$. The percentage mean PCMC score for sub-scales was $87 \%$ for dignity and respect, $54 \%$ for communication and autonomy, and $64 \%$ for supportive care. The figure also showed that from the 
components of person-centered maternity care, dignity and respect recorded the highest percentage mean score followed by supportive care while communication and autonomy received the lowest mean score.

\section{Factors associated with Person-Centered Maternity Care}

In simple linear regression residence, educational level, ANC follow-up, number of ANC, time of delivery, and complication during delivery were factors significantly associated with PCMC score. In multiple linear regression having no ANC follow up, $<4$ ANC follow up, nighttime delivery, and complications during delivery were factors significantly associated with PCMC score.

By controlling the effect of all other variables in the model, mothers who have no ANC follow-up had decreased person-centered maternity care score by a factor of five times as compared to mothers having ANC follow-up ( $\beta=-5.39,95 \% \mathrm{Cl}$ : $-10.52,-0.26)$. Similarly, mothers having $<4$ ANC visits had decreased person-centered maternity care score by a factor of four times as compared to mothers having four or more ANC visits ( $\beta=-3.99,95 \% \mathrm{Cl}:-6.63,-1.36)$.

Respondents who gave birth at night time had decreased person-centered maternity care score by a factor of four times as compared to their counterparts ( $\beta=-3.95,95 \% \mathrm{Cl}:-5.91,-1.98)$. Additionally, mothers who had complications during delivery had decreased PCMC score by a factor of three times as compared to mothers delivered without complications ( $\beta=-3.18,95 \% \mathrm{Cl}:-6.01,-0.35)$ (Table 6). 
Table 6

Bivariate and multivariate linear regression analysis for factors affecting Person-Centered Maternity Care, Addis Ababa, Ethiopia, 2021

\begin{tabular}{|c|c|c|c|}
\hline Variables & $\begin{array}{l}\text { Mean } \\
\text { (SD) }\end{array}$ & Crud $\beta$ & Adjusted $\beta$ \\
\hline \multicolumn{4}{|l|}{ Residence } \\
\hline & $\begin{array}{l}59.8 \\
(10.2)\end{array}$ & \multirow{2}{*}{$\begin{array}{l}1.00 \\
-4.63(-7.45,1.79)^{\star \star}\end{array}$} & \multirow{2}{*}{$\begin{array}{l}1.00 \\
-1.65(-4.82,1.51)\end{array}$} \\
\hline Rural & $\begin{array}{l}55.2 \\
(8.5)\end{array}$ & & \\
\hline \multicolumn{4}{|l|}{ Level of education } \\
\hline Diploma and above & \multirow[t]{2}{*}{$\begin{array}{l}60.3 \\
(11.2)\end{array}$} & & 1.00 \\
\hline Unable to read and write & & $-5.28(-9.96,-0.59)^{\star}$ & $-1.27(-5.96,3.42)$ \\
\hline Primary (grade 1-8) & $(9.6)$ & $-1.93(-4.64,0.78)$ & $-0.50(-3.22,2.22)$ \\
\hline \multirow[t]{2}{*}{ Secondary (grade 9-12) } & $\begin{array}{l}58.4 \\
(9.5)\end{array}$ & \multirow[t]{2}{*}{$0.01(-2.90,2.86)$} & \multirow[t]{2}{*}{$-0.29(-2.48,3.06)$} \\
\hline & $\begin{array}{l}60.3 \\
(10.0)\end{array}$ & & \\
\hline \multicolumn{4}{|l|}{ ANC } \\
\hline Yes & $\begin{array}{l}59.4 \\
(10.0)\end{array}$ & \multirow{2}{*}{$\begin{array}{l}1.00 \\
-6.14(-11.34,-0.95)^{\star}\end{array}$} & \multirow{2}{*}{$\begin{array}{l}1.00 \\
-5.39(-10.52,-0.26)^{\star}\end{array}$} \\
\hline No & $\begin{array}{l}53.8 \\
(11.0)\end{array}$ & & \\
\hline \multicolumn{4}{|l|}{ Number of ANC } \\
\hline Four and above & $\begin{array}{l}60.7 \\
(9.8)\end{array}$ & \multirow{2}{*}{$\begin{array}{l}1.00 \\
-4.96(-6.99,-2.39) \star \star \star\end{array}$} & \multirow{2}{*}{$\begin{array}{l}1.00 \\
-3.99(-6.63,-1.36)^{\star}\end{array}$} \\
\hline Less than four & $\begin{array}{l}55.6 \\
(9.7)\end{array}$ & & \\
\hline \multicolumn{4}{|l|}{ Time of delivery } \\
\hline & $\begin{array}{l}61.1 \\
(10.2)\end{array}$ & & 1.00 \\
\hline Nighttıme & $\begin{array}{l}56.8 \\
(9.5)\end{array}$ & $-4.3(-6.29,-2.31)^{\star * \star}$ & $-3.95(-5.91,-1.98)^{*}$ \\
\hline
\end{tabular}

Keys: 1 = Reference, $\mathrm{Cl}=$ Confidence Interval

$*=p-$ value $<0.05,{ }^{* *}=p-$ value $<0.01, * * *=p-$ value $<0.001$ 


\begin{tabular}{|c|c|c|c|}
\hline Variables & $\begin{array}{l}\text { Mean } \\
\text { (SD) }\end{array}$ & Crud $\beta$ & Adjusted $\beta$ \\
\hline \multicolumn{4}{|c|}{ Complication during delivery } \\
\hline \multirow{2}{*}{$\begin{array}{l}\text { Yes } \\
\text { No }\end{array}$} & $\begin{array}{l}59.6 \\
(9.6)\end{array}$ & \multirow{2}{*}{$\begin{array}{l}1.00 \\
-3.09(-5.97,-0.21)^{*}\end{array}$} & \multirow{2}{*}{$\begin{array}{l}1.00 \\
-3.18(-6.01,-0.35)^{\star}\end{array}$} \\
\hline & $\begin{array}{l}56.5 \\
(12.2)\end{array}$ & & \\
\hline \multicolumn{4}{|c|}{ Keys: 1 = Reference, $\mathrm{Cl}$ = Confidence Interval } \\
\hline \multicolumn{4}{|c|}{$*=p-$ value $<0.05,{ }^{* *}=p$-value $<0.01, * * *=p-$ value $<0.001$} \\
\hline
\end{tabular}

\section{Discussion}

Person-centered maternity care is identified as the key aspect of quality of maternity care that contributes to improved maternal and neonatal outcomes and increased institutional delivery [3]. This study investigated the prevalence of person-centered maternity care and associated factors among mothers who gave birth at public hospitals in Addis Ababa city.

The study reported that the prevalence of person-centered maternity care was $65.8 \%$. The findings of this study indicated that health care providers rarely introduced themselves, asked permission before performing examinations and procedures, involved women in decisions about their care, allowed a position of choice during delivery, explained procedures and the purpose of medications. Most of the mothers were also not allowed to have labor and delivery companions.

The finding of this study is relatively consistent with the studies done in Kenya where the proportion of person-centered maternity care was $66.9 \%$ and a community-based cross-sectional conducted study in Dessie town where the percentage mean person-centered maternity care score was $64.5 \%{ }^{[2,18]}$. This might be due to the similarity in study design and the nature of study participants.

However, the result of this study is lower than a study conducted in Ghana where more than $75 \%$ of women experienced high person-centered maternity care scores ${ }^{[10]}$. This possible reason could be due to socio-cultural and socio-economic differences. The variation might also be due to improved quality of health care and staff training in Ghana.

On the other hand, the finding of this study was higher than a cross-sectional study done in Colombo, Sri Lanka where the mean person-centered maternity care score was 42.3 out of 90 . The reason might be due to the variation in the study setting and the participant's level of reporting the care. The results of this study also showed that a higher level of person-centered maternity care than a study conducted in Bahir Dar town where the prevalence of person-centered maternity care was $57 \%$. The difference might be due to the study period and data collection procedure variation. In addition, it might be due to service improvement in Addis Ababa public hospitals. 
The current study found that respondents who had no ANC follow-up, less than four ANC visits, nighttime delivery, and complications during delivery were factors significantly associated with person-centered maternity care.

Respondents who had no ANC follow-up had significantly decreased person-centered maternity care scores as compared to respondents who have ANC follow-up. This finding is in line with the study done in Eastern Ethiopia ${ }^{[23]}$. This is due to mothers who had no ANC might not have experience with services and they might not develop the confidence to communicate with health care providers in the facility.

Mothers who have less than four ANC visits had negative association with person-centered maternity care as compared to mothers who have four or more visits. It is because when ANC follow-up is not completed the mothers might not be familiar with health care providers that could affect person-centered maternity care. In addition, having infrequent ANC follow-up might decrease utilization of maternal health services that affect the interaction of clients with health care providers and the mothers might perceive that they did not receive person-centered care.

Women's who delivered at nighttime had experienced poor person-centered maternity care as compared to women's who delivered during the daytime. This is consistent with a study conducted in Dessie town ${ }^{[2]}$. The possible justification could be due to the effect of work overload, physical exhaustion and the small number of health professionals at nighttime. Hence, health care providers might not focus on PCMC. Additionally, there might be a lack of resources or weak supervision during the nighttime that could affect the mother's experience of person-centered care.

Respondents who had complications during delivery had significantly decreased person-centered maternity care scores as compared to respondents without complications. This is consistent with a study done in Bahir Dar ${ }^{[22]}$. The reason might be mothers who had a complication during delivery might perceive that they experienced complications due to poor quality of care they received from health care providers. Moreover, mothers with a complication during childbirth are stayed in the facility for a long time without getting support from their families. Besides, they might not be satisfied with the services they received from providers.

\section{Conclusion}

The finding of this study revealed that the proportion of person-centered maternity care during childbirth in public hospitals of Addis Ababa was $65.8 \%$. ANC follow-up, number of ANC follow-up, time of delivery, and complications during delivery were factors significantly associated with person-centered maternity care. The factors affecting person-centered maternity care are manageable to interventions. Therefore, training should be given to health care providers on the importance of person-centered maternity care and patient and provider rights. Health care providers need to improve the awareness of women about the importance of ANC follow-up that could improve their interactions with clients. 


\section{Abbreviations}

ANC- Ante-Natal Care, Cl-Confidence Interval, LMICs- Low and Middle-Income Countries, PCC-Personcentered care, PCMC-Person-Centered Maternity Care, WHO- World Health Organization

\section{Declarations}

\section{ACKNOWLEDGEMENT}

First, we would like to thanks the Almighty God for all the blessings in our lives and for helping us to do this research. Our heartfelt gratitude goes to Addis Ababa University, College of Health Sciences, School of Nursing and Midwifery for giving us the chance to enroll in the postgraduate program. Our deepest gratitude goes to the authors for their unreserved support and relevant comments in carrying out this research. We would like to thank Addis Ababa public hospital administrators for facilitating the data collection process. We would like to extend our appreciation to supervisors, data collectors, and study participants for their collaboration throughout the study period.

\section{Authors' contribution}

AAT conceived the design of the study, developed the tool, coordinated data collection, analyzed the data, and performed statistical analysis. BWG and BM approved the proposal, engaged in data analysis and interpretation by revising subsequent drafts of the article. All authors read and approved the final manuscript.

\section{Funding}

This article was funded by Addis Ababa University, College of Health Sciences, School of Nursing and Midwifery.

\section{Availability of data}

Both Epi-data version 4.6 and SPSS version 25 data of this article is available up on reasonable request from the authors.

\section{Ethics approval and consent to participate}

Ethical clearance to conduct this research was obtained from the research review and ethics committee of Addis Ababa University, College of Health Sciences, School of Nursing and Midwifery. Letter of permission to conduct the study was received from Addis Ababa Public Health Research and Emergency Management Directorate. Each respondent was informed about the purpose and anticipated benefits of the study by the data collectors. Written consent was obtained from volunteer participants. Confidentiality and anonymity were ensured throughout the process of the study. 


\section{Author Details}

${ }^{1}$ St. Paul's Hospital Millennium Medical College

${ }^{283}$ Addis Ababa University, College of Health Sciences, School of Nursing and Midwifery

\section{Competing interests}

The authors declare that they have no competing interests.

\section{Consent for publication}

Not applicable

\section{References}

1. Person-Centered Care. A Definition and Essential Elements. J Am Geriatr Soc. 2016;64(1):15-8.

2. Dagnaw FT, et al. Determinants of person-centered maternity care at the selected health facilities of Dessie town, Northeastern, Ethiopia: community-based cross-sectional study. BMC Pregnancy Childbirth. 2020;20(1):524.

3. Oladapo OT, et al. WHO model of intrapartum care for a positive childbirth experience: transforming care of women and babies for improved health and wellbeing. Bjog. 2018;125(8):918-22.

4. Filler T, et al. Multi-level strategies to tailor patient-centred care for women: qualitative interviews with clinicians. BMC Health Serv Res. 2020;20(1):1-9.

5. Sudhinaraset $\mathrm{M}$, et al. Person-centered maternity care and postnatal health: associations with maternal and newborn health outcomes. AJOG Global Reports. 2021;1(1):100005.

6. Rishard $\mathrm{M}$, et al. Correlation among experience of person-centered maternity care, provision of care and women's satisfaction: Cross sectional study in Colombo, Sri Lanka. Plos one. 2021;16(4):e0249265.

7. Hajizadeh $\mathrm{K}$, et al. Respectful maternity care and its relationship with childbirth experience in Iranian women: a prospective cohort study. BMC Pregnancy Childbirth. 2020;20(1):468.

8. Afulani PA, Sayi TS, Montagu D. Predictors of person-centered maternity care: the role of socioeconomic status, empowerment, and facility type. BMC Health Serv Res. 2018;18(1):360.

9. Rosen HE, et al. Direct observation of respectful maternity care in five countries: a cross-sectional study of health facilities in East and Southern Africa. BMC Pregnancy Childbirth. 2015;15:306.

10. Ocansey K. Assessing Person-Centered Maternity Care at the LEKMA Hospital. University of Ghana; 2019. 
11. Asefa A, Bekele D. Status of respectful and non-abusive care during facility-based childbirth in a hospital and health centers in Addis Ababa, Ethiopia. Reprod Health. 2015;12:33.

12. Abuya $T$, et al. Measuring mistreatment of women throughout the birthing process: implications for quality of care assessments. Reprod Health Matters. 2018;26(53):48-61.

13. Ishola F, Owolabi O, Filippi V. Disrespect and abuse of women during childbirth in Nigeria: A systematic review. PLoS One. 2017;12(3):e0174084.

14. Mengesha MB, et al., Disrespect and Abuse during Childbirth in Ethiopia: A Systematic Review. Biomed Res Int, 2020. 2020: p. 8186070.

15. Sudhinaraset $M$, et al. Advancing a conceptual model to improve maternal health quality: The Person-Centered Care Framework for Reproductive Health Equity. Gates Open Res. 2017;1:1.

16. Kassa ZY, Tsegaye B, Abeje A. Disrespect and abuse of women during the process of childbirth at health facilities in sub-Saharan Africa: a systematic review and meta-analysis. BMC Int Health Hum Rights. 2020;20(1):23.

17. Rubashkin N, Warnock R, Diamond-Smith N. A systematic review of person-centered care interventions to improve quality of facility-based delivery. Reprod Health. 2018;15(1):169.

18. Afulani PA, et al. Person-centred maternity care in low-income and middle-income countries: analysis of data from Kenya, Ghana, and India. Lancet Glob Health. 2019;7(1):e96-109.

19. Ansari $H$, Yeravdekar R. Respectful maternity care during childbirth in India: A systematic review and meta-analysis. J Postgrad Med. 2020;66(3):133-40.

20. Mekonnen A, Fikadu G, Esmeal A. Disrespectful and abusive maternity care during childbirth in Bale zone Public Hospitals, Southeast Ethiopia: Crosssectional study. Clinical Practice. 2019;16(5):127380.

21. Siraj A, Teka W, Hebo H. Prevalence of disrespect and abuse during facility based child birth and associated factors, Jimma University Medical Center, Southwest Ethiopia. BMC Pregnancy Childbirth. 2019;19(1):185.

22. Wassihun B, Zeleke S. Compassionate and respectful maternity care during facility based child birth and women's intent to use maternity service in Bahir Dar, Ethiopia. BMC Pregnancy Childbirth. 2018;18(1):294.

23. Bante A, et al. Respectful maternity care and associated factors among women who delivered at Harar hospitals, eastern Ethiopia: a cross-sectional study. BMC Pregnancy Childbirth. 2020;20(1):86.

24. Bulto GA, Demissie DB, Tulu AS. Respectful maternity care during labor and childbirth and associated factors among women who gave birth at health institutions in the West Shewa zone, Oromia region, Central Ethiopia. BMC Pregnancy Childbirth. 2020;20(1):443.

25. Sheferaw ED, et al. Respectful maternity care in Ethiopian public health facilities. Reprod Health. 2017;14(1):60.

26. World Population projections. Ethiopia Demographics Profile. CIA World.; 2019. 
27. Afulani PA, et al. Validation of the person-centered maternity care scale in India. Reprod Health. 2018;15(1):147.

\section{Figures}

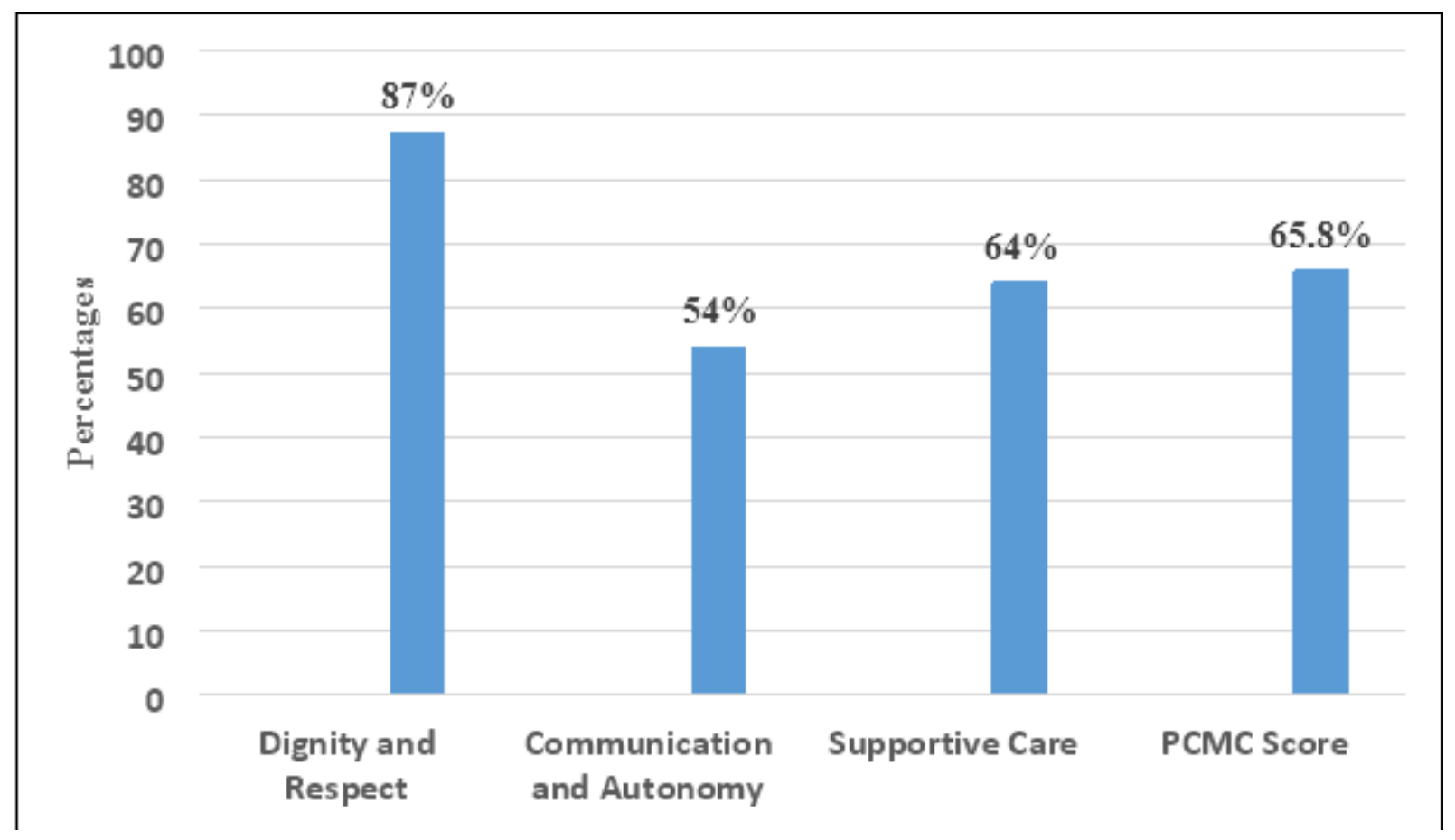

\section{Figure 1}

Distribution of percentage mean score of PCMC scale and subscales in public hospitals of Addis Ababa, Ethiopia, 2021. 